02

\title{
Генерация синглетного кислорода в микрокапиллярных оптических элементах с фотоактивными покрытиями
}

\author{
(C) И.В. Багров ${ }^{1}$, В.М. Киселев ${ }^{1}$, С.К. Евстропьев ${ }^{2,3}$, А.С. Саратовский $^{3}$, \\ B.В. Демидов ${ }^{4}$, А.С. Матросова ${ }^{3,4}$ \\ 1 „ГОИ им. С.И. Вавилова“, \\ Санкт-Петербург, Россия \\ ${ }^{2}$ Санкт-Петербургский государственный технологический институт (Технический университет), \\ 190013 Санкт-Петербург, Россия \\ ${ }^{3}$ Университет ИТМО, \\ 197101 Санкт-Петербург, Россия \\ ${ }^{4}$ АО „НПО „ГОИ им. С.И. Вавилова“, \\ 199052 Санкт-Петербург, Россия \\ e-mail: evstropiev@bk.ru
}

Поступила в редакцию 17.10.2019 г.

В окончательной редакции 17.10.2019 г.

Принята к публикации 28.10.2019 г.

\begin{abstract}
Приведены результаты исследования спектрально-люминесцентных свойств оксидных нанопокрытий, содержащих наночастицы $\mathrm{ZnO}$ и $\mathrm{Ag}$, и процессов генерации в них синглетного кислорода. На основе полученных экспериментальных данных была разработана микроканальная фотоактивная кювета для систем очистки воды и воздуха. Разработанная микроканальная фотоактивная кювета представляет собой оптический элемент, изготовленный из кварцевого стекла с каналами заданной формы, размера и пространственного расположения, содержащими нанокристаллы оксидов цинка и магния, а также наночастицы серебра. Показана высокая эффективность генерации синглетного кислорода покрытиями $\mathrm{ZnO}$ и $\mathrm{ZnO}-\mathrm{MgO}-\mathrm{Ag}$ и микроканальными кюветами под действием УФ излучения $(370 \mathrm{~nm})$ и фиолетового света $(405 \mathrm{~nm})$.
\end{abstract}

Ключевые слова: синглетный кислород, микроканальная мембрана, люминесценция, фотоактивная кювета, Ag-наночастицы.

DOI: $10.21883 / O S .2020 .02 .48963 .281-19$

\section{Введение}

В настоящее время фотокаталитические и бактерицидные оксидные полупроводниковые материалы являются объектом интенсивных исследований и уже широко применяются на практике [1-5].

Использование наноструктурированных композитов обеспечивает усиление антибактериальной активности материалов, улучшает фотокаталитические характеристики материалов. Во многих работах [1-14] исследованы различные фотоактивные композиты и механизмы, определяющие их фотокаталитические и бактерицидные свойства. Установлено [5-14], что композиционные материалы на основе оксида цинка являются одними из наиболее перспективных для использования в качестве фотокатализаторов и обладают высокими антибактериальными свойствами. Так, в $[10,13,14]$ было установлено, что добавки серебра существенно усиливают фотокаталитические и антибактериальные свойства оксида цинка.

Химические активные соединения кислорода (reactive oxygen species, ROS) играют важную роль в фотокаталитических процессах и антибактериальной активности материалов [2,6-8,15-19], и разрабатываются устройства, обеспечивающие формирование этих соединений кислорода в газовых потоках [20,21]. Высокоэффективные мембраны, содержащие наночастицы, разрабатываются для систем очистки воды $[22,23]$. Использование трубчатых капиллярных мембран из прозрачного кварцевого стекла может обеспечить 1) высокую прозрачность такого элемента для эффективной генерации ROS под действием света, 2) большую площадь контакта газового потока со стенками каналов, покрытых фотоактивным покрытием.

Целью настоящей работы является исследование процессов генерации синглетного кислорода в микрокапиллярных структурах, содержащих наночастицы $\mathrm{ZnO}, \mathrm{MgO}$ и $\mathrm{Ag}$.

\section{Материалы и методы}

Для формирования покрытий, содержащих эти наночастицы, был использован полимерно-солевой метод, подробно описанный в $[7,8,11]$. Образование наночастиц серебра в растворе происходило в результате восстановления ионов $\mathrm{Ag}^{+}$поливинилпирролидоном (ПВП) [24-26]. Химические составы пленкообразующих растворов представлены в таблице.

Нанесение покрытий на поверхность плоских пластин из щелочно-силикатного стекла осуществлялось путем 

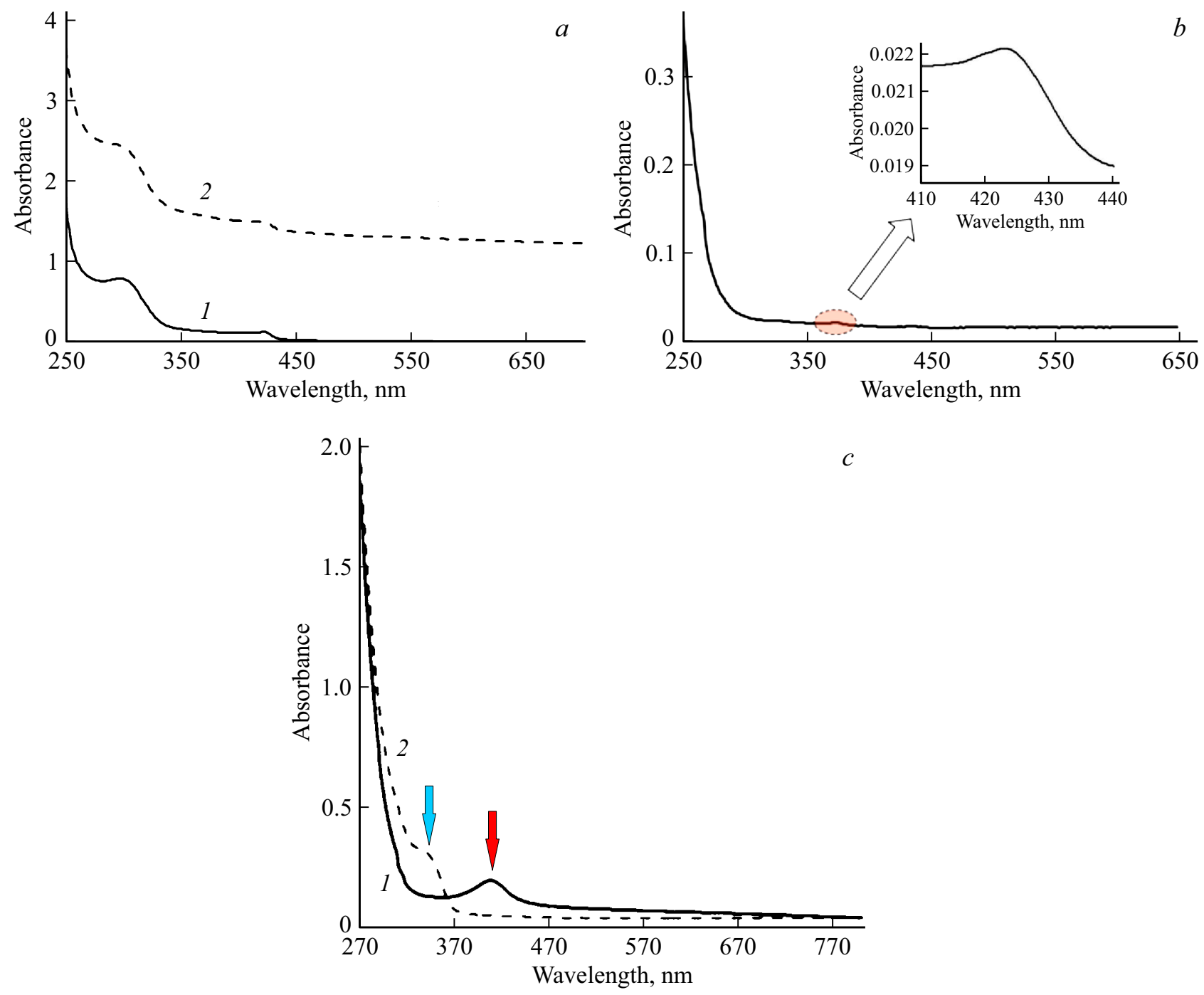

Рис. 1. (a) спектры поглощения раствора 1. Временная выдержка после смешения компонентов: 15 min (кривая 1); 24h (2); $(b)$ спектр поглощения стеклянной пластины с композиционным покрытием, изготовленным из раствора $1 ;(c)$ спектры поглощения стеклянных пластин с оксидными покрытиями, полученными из растворов 1 (кривая 1) и 2 (2).

Химический состав пленкообразующих растворов

\begin{tabular}{c|c|c|c|c|c|c}
\hline Раствор & \multicolumn{5}{|c}{ Содержание компонентов, масс. \% } \\
\cline { 2 - 6 } & Вода & $\begin{array}{c}\text { Пропа- } \\
\text { нол-2 }\end{array}$ & ПВП & $\mathrm{Zn}\left(\mathrm{NO}_{3}\right)_{2}$ & $\mathrm{Mg}\left(\mathrm{NO}_{3}\right)_{2}$ & $\mathrm{AgNO}_{3}$ \\
\hline 1 & 50.24 & 46.60 & 2.37 & 0.69 & 0.06 & 0.04 \\
2 & 96.80 & 0 & 2.90 & 0.30 & 0 & 0
\end{tabular}

их окунания в пленкообразующие растворы с последующим извлечением. Сушка образцов проводилась при комнатной температуре в течение $24 \mathrm{~h}$. Высушенные образцы подвергались термообработке в электропечи при $550^{\circ} \mathrm{C}$ в течение $2 \mathrm{~h}$. Использованный режим термообработки обеспечивает полное разложение нитратов металлов и ПВП и удаление газообразных продуктов [7].
В работе использовались микроструктурированные мембраны из кварцевого стекла, изготовленные по методике, подробно описанной в [27]. Внешний диаметр мембран составлял $3 \mathrm{~mm}$, а длина $70 \mathrm{~mm}$. Диаметр воздушных каналов составлял $0.07-0.25 \mathrm{~mm}$. Измерение спектров поглощения плоских образцов с покрытиями осуществлялось на спектрофотометре Perkin-Elmer Lambda 900 в спектральном диапазоне 200-900 nm.

Определение способности синтезированных оксидных покрытий к генерации синглетного кислорода осуществлялось путем измерения спектров фотолюминесценции покрытий в ближней ИК области спектра по методике, подробно описанной в [15-17]. Для возбуждения фотолюминесценции материала использовалось излучение светодиода HPR40E-50UV (максимум полосы генерации $370 \mathrm{~nm}$ ). Спектры люминесценции исследовались на спектрометре SDH-IV (SOLAR Laser Systems, Республика Беларусь). 

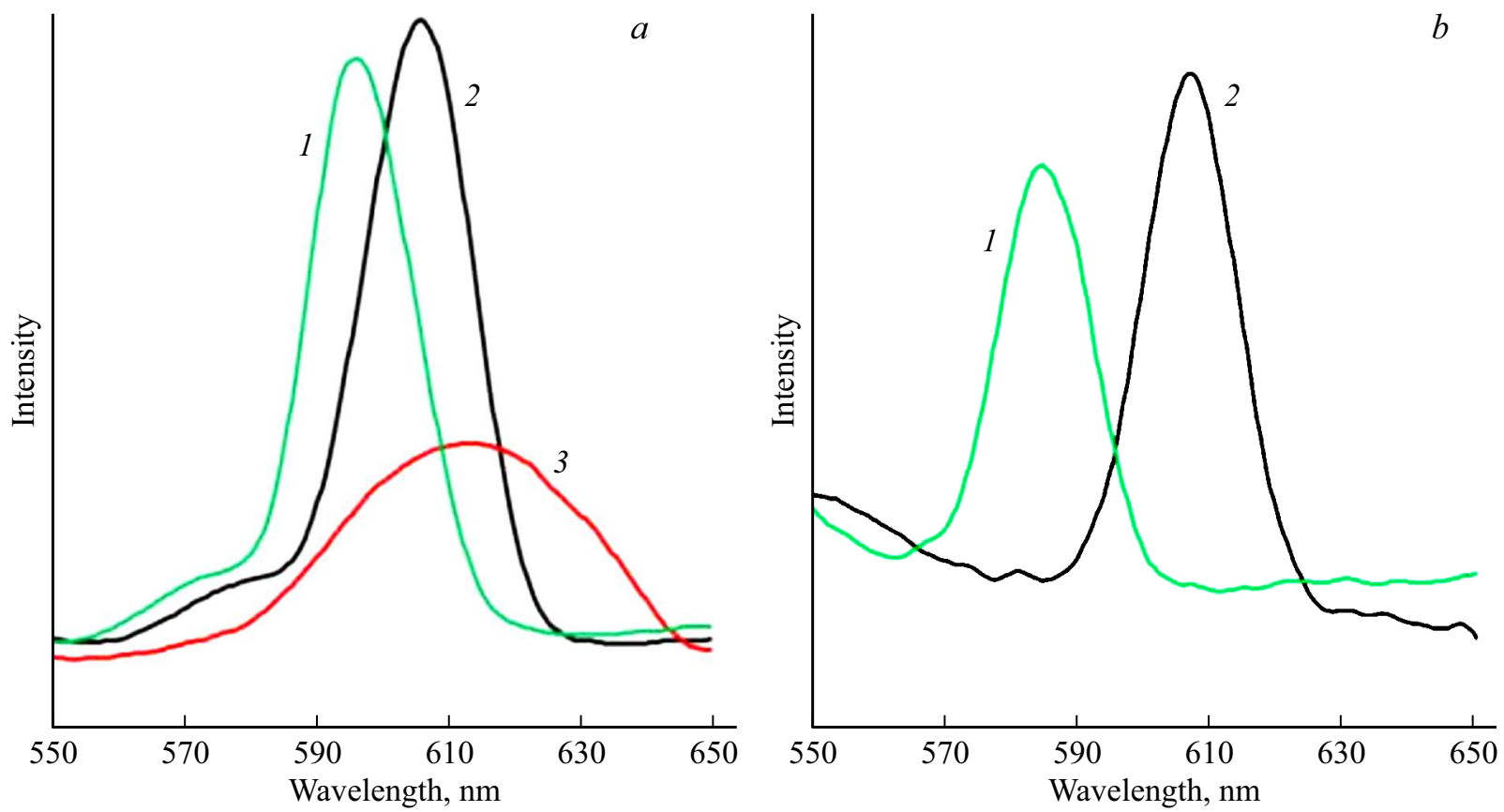

Pис. 2. (a) Спектры фотолюминесценции в видимой области спектра пластины с покрытием, изготовленным из раствора 1. Длина волны возбуждения люминесценции 400 (кривая 1$), 405$ (2), $425 \mathrm{~nm}(3)$; $(b)$ спектры фотолюминесценции в видимой области спектра микроканальной заготовки с покрытием, изготовленным из раствора 1. Длина волны возбуждения люминесценции 400 (кривая 1), $405 \mathrm{~nm}(2)$.

\section{Результаты и обсуждения}

На рис. $1, a$ приведены спектры поглощения пленкообразующего раствора $\mathbf{1}$, измеренные через $15 \mathrm{~min}$ (кривая 1) и $24 \mathrm{~h}(2)$ после смешения компонентов. Из рисунка видно, что в спектрах растворов наблюдаются полосы поглощения с максимумами при 305 и $425 \mathrm{~nm}$. Полоса поглощения с максимумом при $305 \mathrm{~nm}$ обусловлена наличием в растворе нитратов серебра и других металлов $[28,29]$. Более длинноволновая полоса поглощения с максимумом $\sim 425 \mathrm{~nm}$ определяется плазмонным поверхностным резонансом [25,26,30-35] наночастиц $\mathrm{Ag}$, формирующихся в растворе. Образование наночастиц $\mathrm{Ag}$ происходит при восстановлении ионов серебра поливинилпирролидоном $[24,26]$. Временная выдержка раствора приводит к снижению его прозрачности, что может объясняться формированием в нем агрегатов наночастиц. Изменения в спектральных свойствах раствора (рис. 1, $a$ ) при временной выдержке аналогичны изменениям, протекающим в композиционных пленках $\mathrm{AgNO}_{3} /$ ПВП и описанным ранее в [26].

Полученные нами тонкие композиционные покрытия $\mathrm{Zn}\left(\mathrm{NO}_{3}\right)_{2} / \mathrm{Mg}\left(\mathrm{NO}_{3}\right)_{2} / \mathrm{AgNO}_{3} /$ ПВП характеризуются высокой прозрачностью в видимой части спектра. В спектре наблюдается небольшая полоса плазмонного поглощения наночастиц Ag. Сопоставление положения пиков плазмонного поглощения в растворе (рис. $1, a$ ) и в композиционном покрытии (рис. $1, b$ ) показывает, что удаление растворителя в процессе сушки компо- зиционных покрытий практически не изменяет размер наночастиц Ag.

В спектре поглощения образца с покрытием, полученным из раствора $1 \mathrm{c}$ последующей термообработкой при $550^{\circ} \mathrm{C}$ в течение $2 \mathrm{~h}$ (рис. $1, c$ ), наблюдается плазмонная полоса поглощения $\mathrm{Ag}$-наночастиц при $\sim 415 \mathrm{~nm}$ (кривая 1).

Экситонная полоса поглощения наночастиц $\mathrm{ZnO}$ с максимумом при $\sim 350 \mathrm{~nm}$ проявляется в спектре поглощения образца с покрытием, изготовленным из раствора 2. В макроскопических кристаллах $\mathrm{ZnO}$ максимум экситонной полосы поглощения наблюдается при $\sim 370 \mathrm{~nm}$. Сдвиг максимума в коротковолновую часть спектра обусловлен проявлением квантоворазмерного эффекта в наночастицах $\mathrm{ZnO}$.

Радиус $r$ нанокристаллов $\mathrm{ZnO}$ может быть оценен по положению максимума экситонной полосы поглощения по формуле, приведенной в [36]:

$$
r(\mathrm{~nm})=\frac{-0.3049+\sqrt{-26.23+10240.72 / \lambda_{\max }}}{-6.3829+2483.2 / \lambda_{\max }}
$$

где $\lambda_{\max }$ - длина волны пика поглощения, $\mathrm{nm}$. Расчет показал, что размер нанокристаллов $\mathrm{ZnO}$ в покрытии составляет 4-4.5 nm. Аналогичный размер кристаллов $\mathrm{ZnO}$ наблюдался при синтезе наночастиц в растворах, содержащих ПВП [37], и золях оксида цинка, синтезированных в [38]. Малый размер кристаллов покрытия $\mathrm{ZnO}$, полученного из раствора 2 (таблица), определяет его высокую прозрачность в видимой части спектра. 

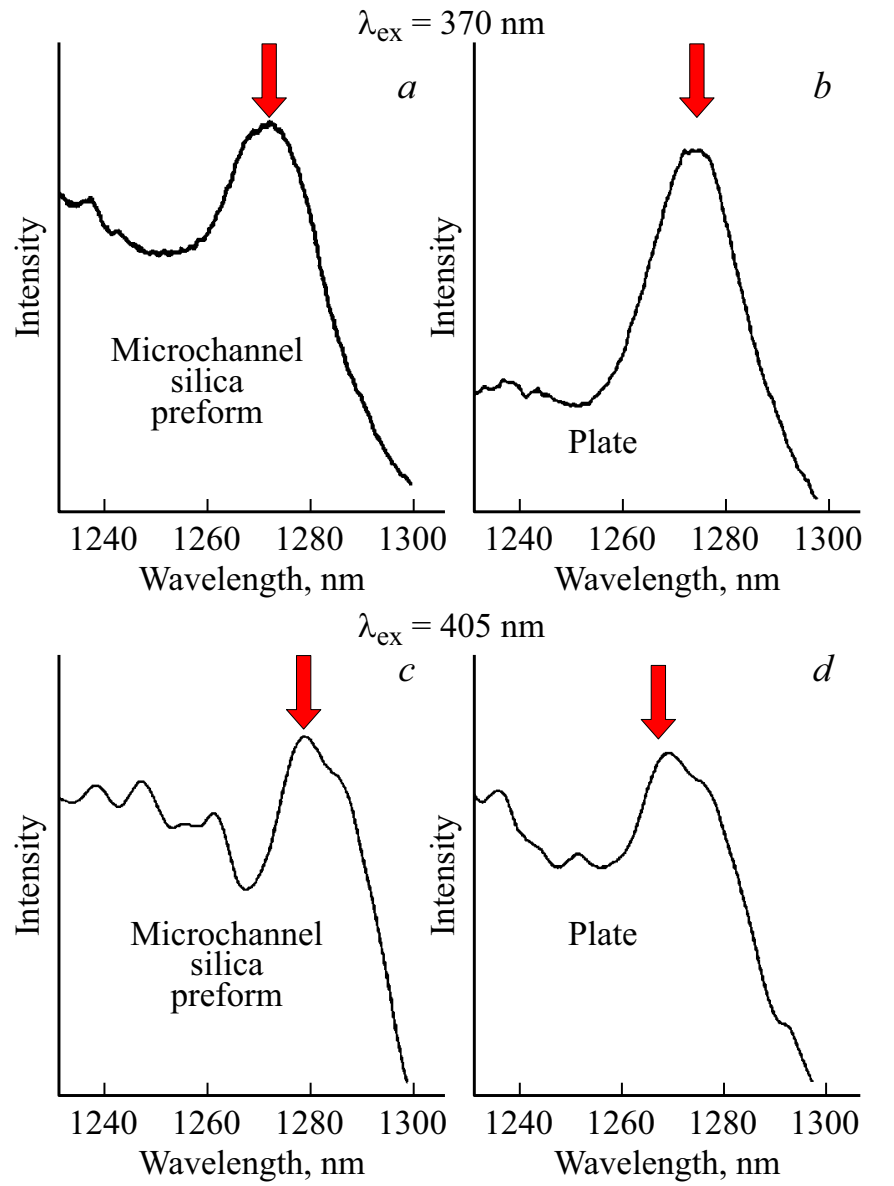

Рис. 3. Спектры фотолюминесценции при возбуждении светом с длиной волны $370(a, b)$ и $405 \mathrm{~nm}(c, d)$ плоских образцов $(b, d)$ и микроканальных заготовок $(a, c)$ с покрытиями $\mathrm{ZnO}$, изготовленными при использовании раствора 2.

Кроме того, большая удельная площадь поверхности этих нанокристаллов определяет эффективный контакт покрытия с окружающей средой и его высокие фотокаталитические и бактерицидные свойства.

Известно (например, [39-43]), что люминесцентные свойства в видимой части спектра Ag-содержащих материалов существенно зависят от структурного состояния серебра (ионы, молекулярные кластеры, наночастицы), его концентрации и свойств окружающей их среды. На рис. 2 приведены спектры фотолюминесценции в видимой области спектра в полученных нами композиционных $(a)$ и оксидных $(b)$ покрытиях. В спектрах покрытий, содержащих Ag, наблюдается довольно интенсивная полоса люминесценции с максимумом $\sim 600 \mathrm{~nm}$. Видно, что интенсивность полосы и положение ее максимума существенно изменяются при варьировании длины волны возбуждающего излучения. Аналогичное явление наблюдалось ранее в [43] в Ag-содержащих пленках полиметилметакрилата.

На рис. 3 приведены спектры фотолюминесценции в ближней ИК области спектра плоских образцов и микроканальных заготовок с покрытиями $\mathrm{ZnO}$, изготовленными при использовании раствора 2 (таблица). Видно, что в спектрах наблюдается полоса люминесценции с максимумом $\lambda \sim 1270 \mathrm{~nm}$, характеристическая для синглетного кислорода [12-16]. Сопоставление спектров люминесценции, полученных для плоских образцов и микроканальных заготовок, показывает отсутствие какого-либо влияния формы изделия, на которое наносилось покрытие, на генерацию синглетного кислорода.

На рис. 4 представлены спектры фотолюминесценции микроканальных мембран с покрытиями $\mathrm{ZnO}$ и $\mathrm{ZnO}-\mathrm{MgO}-\mathrm{Ag}$ на поверхности воздушных каналов (кривые 1 и 2 соответственно). Сопоставление спектров показывает, что интенсивность фотолюминесценции в мембране с композиционным покрытием $\mathrm{ZnO}-\mathrm{MgO}-\mathrm{Ag}$ выше. Эти экспериментальные данные иллюстрируют роль добавок наночастиц Ag в усилении генерации ROS [42] материалов и увеличении их фотокаталитических [6,31] и бактерицидных свойств.

Для сравнения на этом же рисунке приведены спектр фотолюминесценции традиционного макроскопического порошка $\mathrm{ZnO}$ (кривая 3) и спектр покрытия из фуллерена $\mathrm{C}_{60}$, приведенный в работе [43] и уменьшенный по интенсивности в 100 раз для удобства сравнения (кривая 4). Сдвиг максимума люминесценции синглетного кислорода и его более широкий профиль в случае кристаллов фуллерена объясняется наличием в структуре спектра кооперативно-вибронных переходов комплекса молекулы $\mathrm{O}_{2}$ с фуллереном, возникающих под воздействием фононных колебаний решетки фуллерена [4348]. В спектре излучения с поверхности оксидов этого эффекта не наблюдается, хотя в спектре фононных

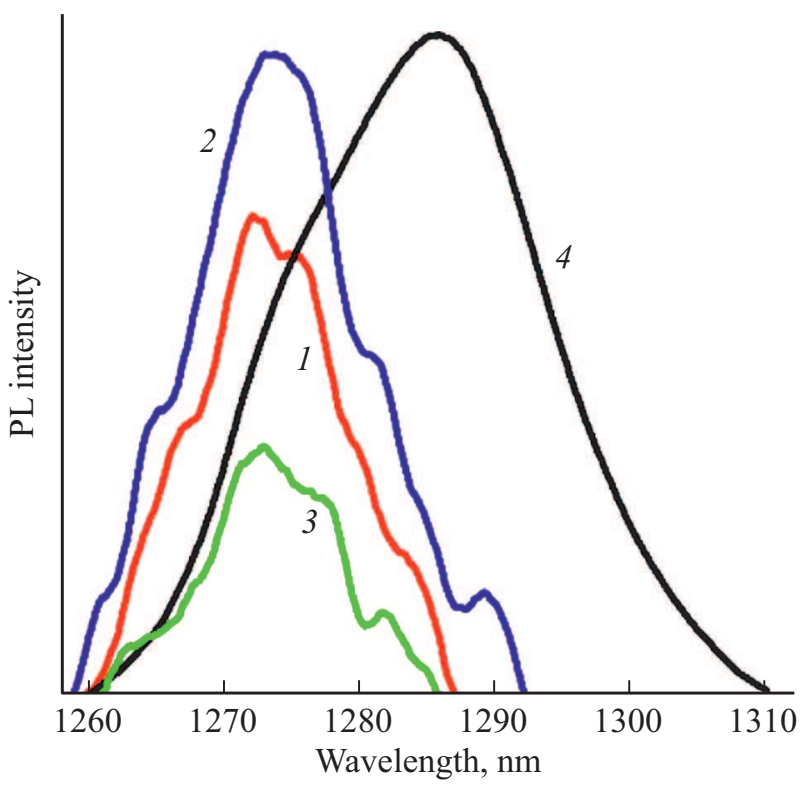

Рис. 4. Спектры фотолюминесценции микроканальной заготовки с покрытиями $\mathrm{ZnO}$ и $\mathrm{ZnO}-\mathrm{MgO}-\mathrm{Ag}$ на поверхности воздушных каналов (кривые 1 и 2 соответственно), порошка оксида цинка (3) и покрытия из фуллерена $\mathrm{C}_{60}(4)$. 
колебаний этого оксида присутствуют частоты в районе 100 и $150 \mathrm{~cm}^{-1}[49,50]$, которые всего в $2-3$ раза выше соответствующих частот кристалла фуллерена $\left(41 \mathrm{~cm}^{-1}\right)$ и могли бы давать заметное уширение спектра люминесценции комплекса кислорода с оксидом цинка. Можно предположить, что в случае с фуллереном наряду с поверхностной сорбцией имеет место значительная объемная сорбция $\mathrm{O}_{2}$ в матрице $\mathrm{C}_{60}[51]$, а в случае синтезированных нами покрытий на основе порошка $\mathrm{ZnO}$ только лишь поверхностная сорбция кислорода, что и определяет это различие. Кстати, в работе [17] отмечается практически одинаковое положение максимума профиля люминесценции синглетного кислорода с поверхности оксидов металлов $\left(\lambda_{\mathrm{m}} \approx 1274 \mathrm{~nm}\right)$ для всех исследованных оксидов.

Сравнение кривых 1 и 3 показывает, что мембрана c $\mathrm{ZnO}$-нанопокрытием обеспечивает более интенсивную генерацию синглетного кислорода по сравнению с традиционным макроскопическим порошком оксида цинка. Это явление полностью согласуется с экспериментальными данными [12] о повышении антибактериальной активности оксида цинка при уменьшении размеров частиц материала.

\section{Заключение}

Нанокомпозитные покрытия $\mathrm{ZnO}-\mathrm{MgO}-\mathrm{Ag}$ сформированы на поверхности воздушных каналов прозрачных микроканальных мембран из кварцевого стекла. Для синтеза были использованы растворы, содержащие нитраты металлов и ПВП, что обеспечивало формирование прозрачных и однородных покрытий, содержащих наночастицы Ag. Экспериментально показана высокая эффективность генерации синглетного кислорода покрытиями и микроканальными мембранами под действием УФ излучения $(370 \mathrm{~nm})$ и фиолетового света $(405 \mathrm{~nm})$.

\section{Финансирование работы}

Работа была частично (Евстропьев С.К., Демидов В.В., Матросова А.С.) поддержана грантом Российского научного фонда № 19-19-00596.

\section{Конфликт интересов}

Авторы заявляют, что у них нет конфликта интересов.

\section{Список литературы}

[1] Wang L., Hu C., Shao L. // Int. J. Nanomed. 2017. V. 2. P. 1227.

[2] Vatansever F., de Melo W.C.M.A., Avci P., Vecchio D., Sadasivam M., Gupta A., Chandran R., Karimi M., Parizotto N.A., Yin R., Tegos G.P., Hamblinn M.R. // FEMS Microbiology Rev. 2013. V. 37. N 6. P. 955.

[3] Rai M., Ingle A.P., Gaikwad S., Gupta I., Gade A., de Silva S.S. // J. Appl. Microbiol. 2015. V. 120. P. 527.
[4] Gaya U.I., Abdullah A.N. // J. Photochem. Photobiol. C: Photochem. Rev. 2008. V. 9. P. 1.

[5] Johar M.A., Afzal R.A., Alazba A.A., Manzoor U. // Advances in Materials Science and Engineering. 2015. V. 2015. Article ID 934587. 22 p. http://doi.org/10.1155/2015/934587.

[6] Fageria P., Gangopadhyay S., Pande S. // RSC Adv. 2014. V. 4. P. 24962. doi 10.1039/c4ra03158j

[7] Evstropiev S.K., Karavaeva A.V., Dukelskii K.V., Kiselev V.M., Evstropyev K.S., Nikonorov N.V., Kolobkova E.V. // Ceram. Int. 2017. V. 43. P. 14504-14510.

[8] Evstropiev S.K., Dukelskii K.V., Karavaeva A.V., Vasilyev V.N., Kolobkova E.V., Nikonorov N.V., Evstropyev K.S. // J. Mater. Sci.: Mater. in Medicine. 2017. V. 28. N 7. Article 102. doi 10.1007/s10856-017-5909-4

[9] Thongrom B., Amornpitoksuk P., Suwanboon S., Baltusatis J. // Korean J. Chem. Eng. 2014. V. 31. N 4. P. 587.

[10] Cheng Z., Zhao S., Han L. // Nanoscale. 2018. V. 10. P. 6892.

[11] Boltenkov I.S., Kolobkova E.V., Evstropiev S.K. // J. Photochem. Photobiol. A: Chemistry. 2018. V. 367. P. 458.

[12] Padmavathy N., Vijayaraghavan R. // Sci. Technol. Adv. Mater. 2008. V. 9. N 3. 035004. doi 10.1088/14686996/9/3/035004

[13] Ravishankar T.N., Manjunatha K., Ramakrishnappa T., Nagaraju G., Kumar D., Sarakar S., Anandakumar B.S., Chandrappa G.T., Reddy V., Dupont J. // Mater. Sci. in Semicond. Proc. 2014. V. 26. P. 7.

[14] Pyne S., Sahoo G.P., Bhui D.K., Bar H., Sarkar P., Samanta S., Maity A., Misra A. // Spectrochim. Acta A: Molec. Biomolec. Spectr. 2012. V. 93. P. 100.

[15] Krasnovsky A.A. jr., Ambartzumian R.V. // Chem. Phys. Lett. 2004. V. 400. P. 531.

[16] Toshihiro D., Yoshio N. // J. Phys. Chem. C. 2007. V. 111. P. $4420-4424$.

[17] Киселев В.М., Кисляков И.М., Бурчинов А.Н. // Опт. и спектр. 2016. Т. 120. № 4. С. 520; Kiselev V.M., Kislyakov I.M., Burchinov A.N. // Opt. Spectrosc. 2016. V. 120. N 4. P. 520.

[18] Santiago-Gonzalez B., Monguzzi A., Caputo M., Villa C., Prato M., Santambrogio C., Torrente Y., Meinardi F., Brovelli S. // Sci. Rep. 2017. V. 7. Article number 5976.2017.

[19] Киселев В.М., Евстропьев С.К., Стародубцев А.М. // Опт. и спектр. 2017. Т. 123. № 5. С. 798; Kiselev V.M., Evstropiev S.K., Starodubtsev A.M. // Opt. Spectrosc. 2017. V. 123. N 5. P. 809.

[20] Багров И.В., Белоусова И.М., Киселев В.М., Кисляков И.М. // Оптический журнал. 2019. Т. 86. № 2. С. 3; Bagrov I.V., Belousova I.M., Kiselev V.M., Kislyakov I.M. // J. Opt. Technology. 2019. V. 68. N 2. P. 66.

[21] Багров И.В., Белоусова И.М., Гренишин А.С., Киселев В.М., Кисляков И.М., Соснов Е.Н. // Опт. и спектр. 2012. T. 112. № 6. C. 1009; Bagrov I.V., Belousova I.M., Grenishin A.S., Kiselev V.M., Kislyakov I.M., Sosnov E.N. // Opt. Spectrosc. 2012. V. 112. N 6. P. 935.

[22] Chung Y.T., Ba-Abbad M.M., Mohammad A.W., Benamor A. // Desalination and Water Treatment. 2016. V. 57. N 17. P. 7801.

[23] Jhaveri J.H., Murthy Z.V.P. // Desalination and Water Treatment. 2016. V. 57. N 55. P. 26803. doi 10.1080/19443994.2015.1120687

[24] Wang H., Qiao X., Chen J., Wang X., Ding S. // Mater. Chem. Phys. 2005. V. 94. P. 449.

[25] Jia K., Wang P., Yuan L., Zhou X., Chen W., Liu X. // J. Mater. Chem. 2015. V. 3. P. 3522. 
[26] Kan C., Cai W., Li C., Zhang L. // J. Mater. Res. 2005. V. 20. N 4. P. 320

[27] Демидов В.В., Дукельский К.В., Шевандин В.С. // Оптический журнал. 2010. Т. 77. № 6. С. 51; Demidov V.V., Dukel'skii K.V., Shevandin V.S. // J. Optical Technology. 2010. V. 77(6). P. 394.

[28] Mack J., Bolton J.R. // J. Photochem. Photobiol. A: Chemistry. 1999. V. 128. P. 1.

[29] Волкова Н.А., Евстропьев С.К., Истомина О.В., Колобкова Е.В. // Опт. и спектр. 2018. Т. 124. № 4. C. 472; Volkova N.A., Evstropiev S.K., Istomina O.V., Kolobkova E.V. // Opt. Spectrosc. 2018. V. 124. N 4. P. 489.

[30] Bohren C.F., Huffman D.R. // Absorption and Scattering of Light by Small Particles / Ed. by Bohren C.F., Huffman D.R. NY:: Wiley, 1983. P. 373.

[31] Zhang X.-F., Liu Z.-G., Shen W., Gurunathan S. // Int. J. Mol. Sci. 2016. V. 17. N 9. P. 1534. doi 10.3390/ijms17091534

[32] He R., Qian X., Yin J., Zhu Z. // J. Mater. Chem. 2002. N 12. P. 3783. doi $10.1039 / \mathrm{B} 205214 \mathrm{H}$

[33] Kelly K.L., Coronado E., Zhao L.L., Schatz G.C. // J. Phys. Chem. B. 2003. V. 107. N 3. P. 668. doi 10.1021/jp026731y

[34] Paramelle D., Sadavoy A., Gorelik S., Free P., Hobley J., Fernig D.G. // Analyst. 2014. V. 139. P. 4855. doi 10.1039/C4AN00978A

[35] Huang T., Xu X.-H.N. // J. Mater. Chem. 2010. V. 20. P. 9867.

[36] Talam S., Karumuri S.R., Gunnam N. // ISRN Nanotechnology. 2012. V. 2012. Art. ID 372505, 6 pages. doi 10.5402/2012/372505

[37] Evstropiev S.K., Vasilyev V.N., Nikonorov N.V., Kolobkova E.V., Volkova N.A., Boltenkov I.A. // Chemical Engineer. and Proc.: Proc. Intensification. 2018. V. 134. P. 45. doi 10.1016/j.cep.2018.10.020

[38] Шапорев А.С., Ванецев А.С., Кирюхин Д.П., Соколов М.Н., Бузник В.М. // Конденсированные среды и межфазные границы. 2011. Т. 13. № 3. С. 374.

[39] Zhang A., Zhang J., Fang Y. // J. Luminescence. 2008. V. 128. N 10. P. 1635.

[40] Guidelli E.J., Baffa O., Clarke D.R. // Sci. Reports. 2015. V. 5. Art. nr 14004.

[41] Basak D., Karan S., Mallik B. // Chem. Phys. Lett. 2006. V. 420. P. 115.

[42] Wan C., Tai J., Zhang J., Guo Y., Zhu Q., Ling D., Gu F., Zhu C., Wang Y., Liu S., Wei F., Cai Q. // Cell Death and Disease. 2019. V. 10. Art. nr 392.

[43] Kiselev V.M., Bagrov I.V. // Opt. Spectrosc. 2017. V. 123. N 4. P. 543.

[44] Nissen M.K., Wilson S.M., Thewalt M.L.W. // Phys. Rev. Lett. 1992. V. 69 (16). P. 2423.

[45] Минаев Б.Ф. // Успехи химии. 2007. Т. 76. N 11. С. 1059.

[46] Wang J., Leng J., Yang H., Sha G., Zhang C. // Langmuir. 2013. V. 29. N 29. P. $9051-9056$.

[47] Minaev B. // Chem. and Chem. Technology. 2016. V. 10. N 4(s). P. 519.

[48] Bregnhøj M., Westberg M., Minaev B.F., Ogilby P.R. // Acc. Chem. Res. 2017. V. 50. P. 1920.

[49] Мельничук С.В., Соколов В.И., Суркова Т.П., Чернов В.М. // ФТТ. 1991. Т. 33. № 11. С. 3247.

[50] Silambarasan M., Saravanan S., Soga T. // Int. J. ChemTech Res. 2014-2015. V. 7(3). P. 1644.

[51] Assink R.A., Schirber J.E., Loy D.A., Morosin B., Carlson G.A. // J. Mater. Res. 1992. V. 7. N 8. P. 2136. 